\title{
Endoscopic ultrasound-guided cholecystogastrostomy as an alternative biliary drainage route in malignant obstructions
}

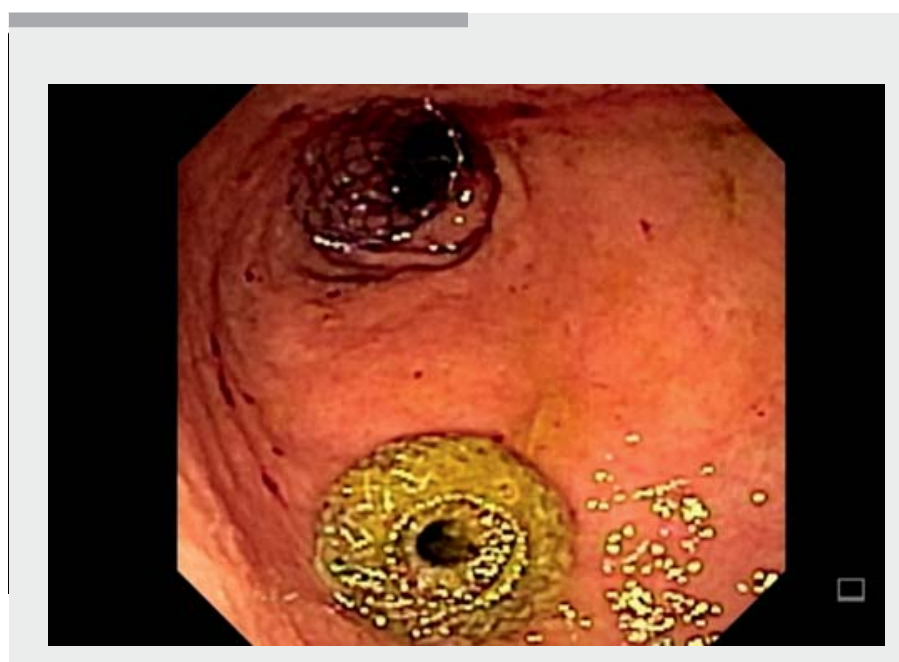

$\checkmark$ Video 1 Endoscopic ultrasound-guided cholecystogastrostomy as an alternative biliary drainage route in a patient with malignant obstruction.

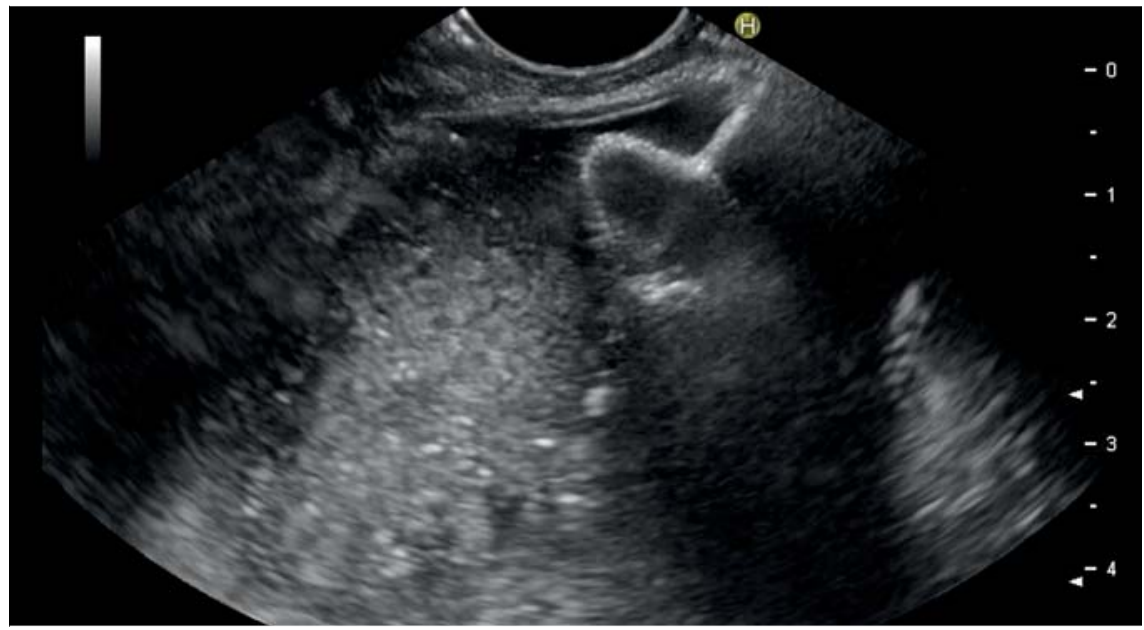

- Fig. 1 Endoscopic ultrasound view showing deployment of a lumen-apposing metal stent in the gallbladder.

Malignant biliary obstruction is a common complication of pancreatic adenocarcinoma, cholangioadenocarcinoma, and other tumors. Biliary drainage is necessary for the management of jaundice, cholangitis, and other debilitating symptoms, such as abdominal pain. Because endoscopic retrograde cholangiopancreatography (ERCP) drainage is not al- ways feasible (owing to severe invasion of the bile duct and/or duodenal wall), endoscopic ultrasound-guided biliary drainage (EUS-BD) has appeared as a promising alternative $[1,2]$. EUS-BD has the advantage of allowing different access routes, depending on the biliary anatomy and the level of the tumor obstruction $[3,4]$.

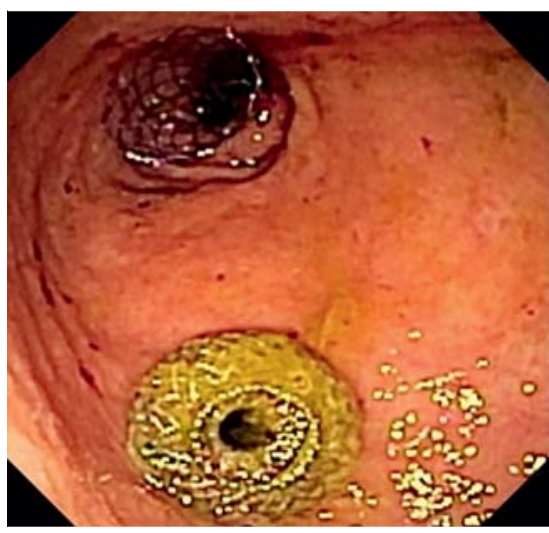

- Fig. 2 Endoscopic view showing the lumen-apposing metal stent and the duodenal self-expandable metal stent.

An 87-year-old woman was diagnosed with ductal pancreatic adenocarcinoma associated with gastric, duodenal, and celiac trunk invasion. While undergoing palliative treatment, she had undergone placement of a biliary self-expandable metal stent (SEMS) 7 months previously. The patient was referred for a new endoscopic biliary drainage procedure because of obstruction of the previous biliary stent and worsening of her clinical condition, associated with jaundice, chills, and several episodes of fever. An ERCP approach was attempted but, owing to the severe tumor invasion of the duodenum, the ampullary region could not be accessed endoscopically. As an alternative, an EUS-guided cholecystogastrostomy was performed through a transgastric approach using an electrocauteryenhanced lumen-apposing metal stent (EC-LAMS; Hot Axios; $10 \times 10 \mathrm{~mm}$; Boston Scientific, Marlborough, Massachusetts, USA) in the same procedure ( $>$ Video $\mathbf{1}$; - Fig. 1). In addition, a duodenal SEMS was placed to prevent further obstruction of the gastrointestinal flow in future ( $\triangleright$ Fig.2). Following this procedure, the patient showed clinical and laboratory improvement, with resolution of her infective symptoms. 
Endoscopy_UCTN_Code_TTT_1AS_2AD

Competing interests

The authors declare that they have no conflict of interest.

The authors

Marco A. D’Assuncao, Fernando P. Marson, Saverio T. N. Armellini, Fernando L. Mota, Fernando J. S. de Oliveira, Eduardo M. A. Pereira Junior

Department of Digestive Endoscopy, Hospital Sírio-Libanês, São Paulo, Brazil

Corresponding author

Fernando Pavinato Marson, MD

Department of Digestive Endoscopy, Hospital Sírio-Libanês, Rua Dona Adma Jafet, 91, São Paulo, Brazil

marsonfp@gmail.com

\section{References}

[1] Choi JH, Lee SS, Choi JH et al. Long-term outcomes after endoscopic ultrasonography-guided gallbladder drainage for acute cholecystitis. Endoscopy 2014; 46: 656-661

[2] Itoi T, Binmoeller KF, Shah J et al. Clinical evaluation of a novel lumen-apposing metal stent for endosonography-guided pancreatic pseudocyst and gallbladder drainage (with videos). Gastrointest Endosc 2012; 75 870-876

[3] Kozakai F, Kanno Y, Ito K et al. Endoscopic ultrasonography-guided gallbladder drainage as a treatment option for acute cholecystitis after metal stent placement in malignant biliary strictures. Clin Endosc 2019; 52: 262-268

[4] Dhir V, Isayama H, Itoi T et al. Endoscopic ultrasonography-guided biliary and pancreatic duct interventions. Dig Endosc 2017; 29: 472-485
Bibliography

Endoscopy 2021; 53: E277-E278

DOI 10.1055/a-1261-2771

ISSN 0013-726X

published online 1.10 .2020

(c) 2020. Thieme. All rights reserved.

Georg Thieme Verlag KG, Rüdigerstraße 14,

70469 Stuttgart, Germany

\section{ENDOSCOPY E-VIDEOS}

https://eref.thieme.de/e-videos

口. Endoscopy E-Videos is a free

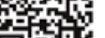
access online section, reporting on interesting cases and new techniques in gastroenterological endoscopy. All papers include a high quality video and all contributions are freely accessible online.

This section has its own submission website at

https://mc.manuscriptcentral.com/e-videos 